\title{
Fracture toughness and reliability in high-temperature structural ceramics and composites: Prospects and challenges for the 21st Century
}

\author{
SUNIL DUTTA \\ National Aeronautics and Space Administration, John Glenn Research Centre, Cleveland, Ohio 44135, USA
}

\begin{abstract}
The importance of high fracture toughness and reliability in $\mathrm{Si}_{3} \mathrm{~N}_{4}$, and $\mathrm{SiC}$-based structural ceramics and ceramic matrix composites is reviewed. The potential of these ceramics and ceramic matrix composites for high temperature applications in defence and aerospace applications such as gas turbine engines, radomes, and other energy conversion hardware have been well recognized. Numerous investigations were pursued to improve fracture toughness and reliability by incorporating various reinforcements such as particulate-, whisker-, and continuous fibre into $\mathrm{Si}_{3} \mathrm{~N}_{4}$ and $\mathrm{SiC}$ matrices. All toughening mechanisms, e.g. crack deflection, crack branching, crack bridging, etc essentially redistribute stresses at the crack tip and increase the energy needed to propagate a crack through the composite material, thereby resulting in improved fracture toughness and reliability. Because of flaw insensitivity, continuous fibre reinforced ceramic composite (CFCC) was found to have the highest potential for higher operating temperature and longer service conditions. However, the ceramic fibres should display sufficient high temperature strength and creep resistance at service temperatures above $1000^{\circ} \mathrm{C}$. The greatest challenge to date is the development of high quality ceramic fibres with associate coatings able to maintain their high strength in oxidizing environment at high temperature. In the area of processing, critical issues are preparation of optimum matrix precursors, precursor infiltration into fibre array, and matrix densification at a temperature, where grain crystallization and fibre degradation do not occur. A broad scope of effort is required for improved processing and properties with a better understanding of all candidate composite systems.
\end{abstract}

Keywords. CFCC; toughening; fracture toughness; $\beta-\mathrm{Si}_{3} \mathrm{~N}_{4}$.

\section{Introduction}

For the last two decades significant progress has been made in improving fracture toughness and reliability in $\mathrm{Si}_{3} \mathrm{~N}_{4^{-}}$and $\mathrm{SiC}$-based ceramics and composites for advanced propulsion systems, such as gas turbine engines where these materials are envisioned for the hot section components. However, these ceramics are brittle because of covalent and ionic bonding that is characteristic of this class of material. No or very little yield can occur as a result of strong bonding which results in large stress concentrations to develop at a crack tip and cause the crack tip to propagate with little expended energy. This results in material with low fracture toughness $\left(K_{\mathrm{IC}}\right)$. For example, typical monolithic polycrystalline silicon nitride materials have fracture toughness in the range 4-6 MPa $\sqrt{m}$ (Campbell and Rahaiby 1995) while silicon carbide ( $\mathrm{SiC}$ ) has fracture toughness in the range 3-4 MPa $\sqrt{\mathrm{m}}$. In contrast, metals have much greater toughness because plastic deformation occurs at the crack tip, which effectively blunts the crack and prevents large stress concentrations. Therefore, in order to improve the fracture toughness of these ceramics, numerous investigations were pursued around the world in the area of ceramic matrix composites (CMCs). The investigations include particulate-, nano-particulate-, whisker-, fibre reinforced-composites, including in situ toughening.

\section{Toughening mechanisms}

In most $\mathrm{CMCs}$, the various mechanisms for toughening are crack deflection, microcracking, transformation toughening, crack branching, and crack bridging. All of these mechanisms essentially redistribute stress at the crack tip and increase the energy needed to propagate a crack through the composite material, thereby resulting in improved toughening. In general, particulate reinforced $\mathrm{Si}_{3} \mathrm{~N}_{4}$ and $\mathrm{SiC}$ composites did not result in noticeable improvement in fracture toughness $\left(K_{\mathrm{IC}}\right)$. For example, typically the fracture toughness of $\mathrm{SiC}$-particulate reinforced $\mathrm{Si}_{3} \mathrm{~N}_{4}$ composites falls in the range $3 \cdot 5-5 \mathrm{Mpa} \sqrt{\mathrm{m}}$ (Campbell and Rahaiby 1995). However, SiC-nano particulate reinforced $\mathrm{Si}_{3} \mathrm{~N}_{4}$ composite has higher $K_{\text {IC }}$ values ranging between 5.3 and $7 \mathrm{MPa} \sqrt{\mathrm{m}}$ (Sawaguchi et al 1991). All composites were fabricated with varying amounts of yttria, or yttria/alumina as sintering aids. In the area of $\mathrm{SiC}-$ whisker reinforced $\mathrm{Si}_{3} \mathrm{~N}_{4}$ composites, fracture toughness values ranging between 6 and $8 \mathrm{MPa} \sqrt{ } \mathrm{m}$ were routinely achieved (Campbell and Rahaiby 1995). The predominant toughening mechanisms in these 
particulate composites were crack deflection with intermittent crack branching, while in SiC-whiskers reinforced composites, whisker pullout was predominant. On the other hand, in situ grown monolithic $\mathrm{Si}_{3} \mathrm{~N}_{4}$ ceramics with yttria/alumina sintering additives, resulted in much improved fracture toughness values ranging from 8-11 MPa $\sqrt{ } \mathrm{m}$, due to the formation of elongated $\beta-\mathrm{Si}_{3} \mathrm{~N}_{4}$ grains with high aspect ratios ( $\mathrm{Li}$ and Yamanis 1989). The toughening mechanisms in this engineered microstructure include a combination of crack deflection, bridging, and whisker-like grain pull out (Morscher et al 1993).

However, despite this improved fracture toughness $\left(K_{\mathrm{IC}}\right)$ in $\mathrm{Si}$-based ceramics, it was understood later, that flaws can develop at any stage during service condition and lifetime of a ceramic component, i.e. during processing, machining, or service, etc (DiCarlo and Dutta 1995). Therefore, production of flaw-free structural or engineering ceramics was seen as an impractical route for fabrication of high strength ceramics. Also, it was felt that the high initial strength is not a solution if the material is readily degraded as a result of service conditions. Further, eliminating flaws did marginal to enhance the reliability or toughness of the ceramic throughout the duration of its operational lifetime. Subsequently, the research focus expanded to develop continuous fibre reinforced ceramic matrix composites (CFCC) because of much greater flaw insensitivity and potential for delayed failure, as compared to particulate-, whisker-reinforced, chopped fibres, and in situ grown composites. The advantages of continuous fibre reinforced ceramic composites (CFCC) are, improved toughness by crack deflection and crack bridging mechanisms, and increased modulus and stress to strain in failure.

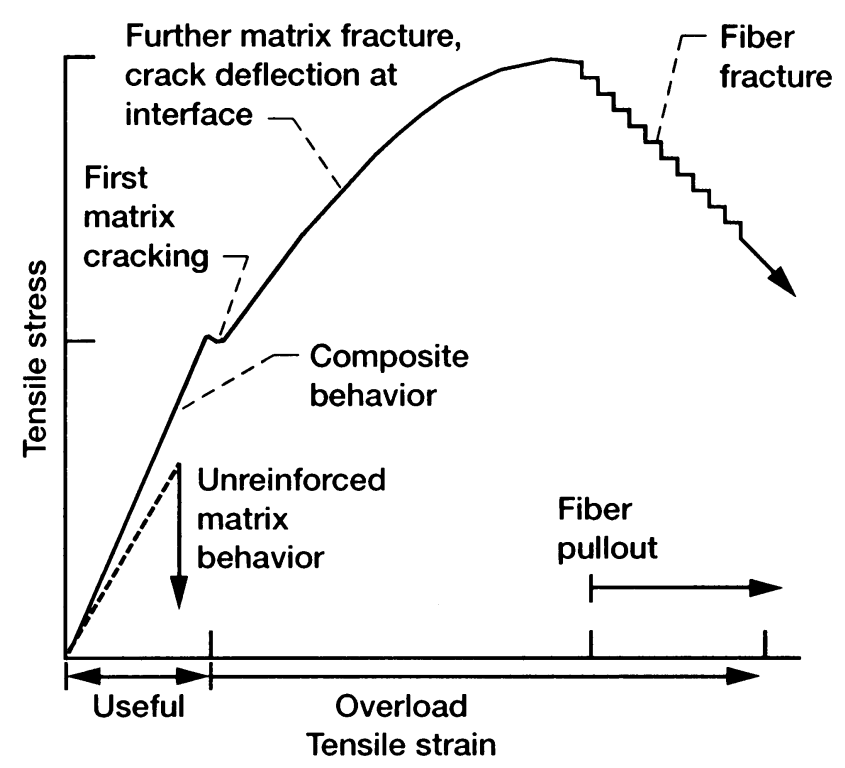

Figure 1. Idealized stress-strain behaviour of continuous fibre-reinforced ceramic matrix composites.

\section{Design criteria}

Figure 1 shows the tensile stress-strain behaviour considered desirable for a structurally reliable CFCC (DiCarlo and Dutta 1995). There are generally three regions in the stress-strain curve: (i) a region of linear stress-strain behaviour before matrix cracking; (ii) a nonlinear region after matrix cracking where multiple matrix cracking occurs without fibre fracture; and (iii) a region of decreasing stress where fibre fracture and pullout occur. Figure 2 shows a typical fracture pattern of a chemically vapour infiltrated (CVI) ceramic grade (CG)-Nicalon $\mathrm{SiC}_{f} / \mathrm{C} / \mathrm{SiC}$ composite material indicating gradual fibre fracture and fibre pullouts. For high-temperature applications requiring long term durability, design below the point of first matrix cracking is preferable because it avoids degradation in composite stiffness, oxidation resistance, fatigue resistance, and thermal conductivity. Composite theories indicate that the matrix cracking point can be enhanced by increasing the fibre volume fraction in the composite and by selecting fibres with the smallest diameter, highest modulus, and greatest creep resistance at the service temperature. It is also very important that the fibre and matrix have nearly equivalent thermal expansion characteristics in order to avoid detrimental expansion-included residual stress within the CFCC. When these guidelines are followed, the matrix cracking point occurs at stress and strain levels that are generally higher and more reproducible than those for the unreinforced matrix itself. In addition, due to significantly higher fracture toughness $\left(K_{\mathrm{IC}}\right)$ and flaw insensitivity of the ceramic composite, the point of first matrix cracking degrades less with time than that for unreinforced matrix under the same service condi-
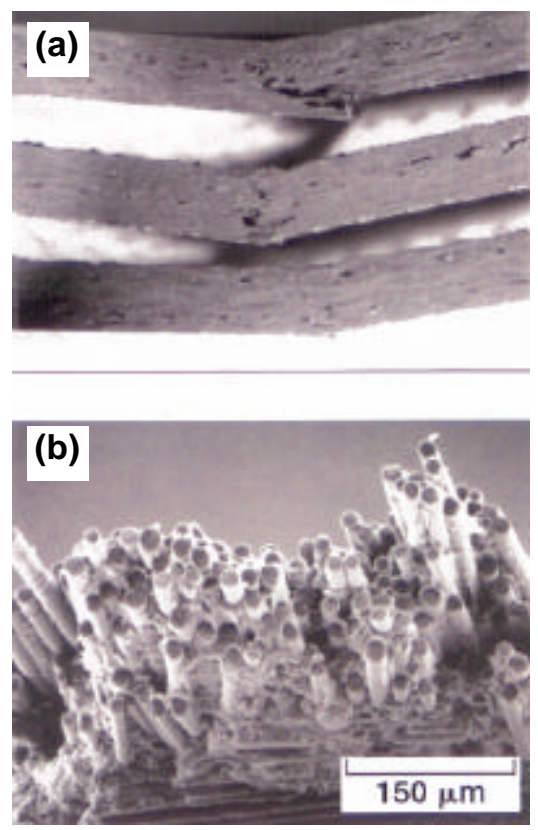

Figure 2. Bend test fracture appearance of $\mathrm{SiC}$ reinforced $\mathrm{SiC}$ composite showing (a) delayed fracture and (b) fibre pullouts. 
tions (DiCarlo and Dutta 1995). Since CFCC will probably have their greatest challenge in long-term temperature applications under oxidizing conditions, the ceramic fibres should be able to maintain high fracture strengths at high temperatures for long times, even when exposed to oxygen containing environments.

Thus the key to high temperature and commercially viable CFCC is the judicious selection and incorporation of continuous ceramic fibres which display the qualitative property needs and is summarized in table 1 (DiCarlo and Dutta 1995). Two most critical fibre needs in table 1 are thermomechanical stability (strength retention and creep resistance) and oxidative stability at temperatures above $1000^{\circ} \mathrm{C}$. Although many commercial carbon and graphite fibres can satisfy most of the table 1 property needs, including thermomechanical stability, they are not considered for long term CFCC applications because of their rapid oxidation above $400^{\circ} \mathrm{C}$. Over the last two decades, this carbon oxidation problem has led to a strong focus on the development and production of continuous ceramic fibres with compositions based on $\mathrm{SiC}, \mathrm{Si}_{3} \mathrm{~N}_{4}$, and alumina compounds.

\section{Fibre processing}

Although significant progress has been made in producing current commercial high strength $\mathrm{SiC}$ fibres such as Nicalon, Hi-Nicalon, and Hi-Nicalon Type S, it is seen that due to process-related factors, these fibres cannot retain their as-produced strengths for composite fabrications conditions above $1200^{\circ} \mathrm{C}\left(2192^{\circ} \mathrm{F}\right)$ (figure 3$)$, or for composite service conditions above $800^{\circ} \mathrm{C}\left(1472^{\circ} \mathrm{F}\right)$ (figure 4) (DiCarlo and Dutta 1995). Because these issues severely limit composite fabrication and use temperatures and thus their technical and commercial viability, fibre manufacturers are examining new and improved processing approaches, which attempt to eliminate or minimize the microstructural sources for fibre strength degradation. For example, the new CVD monofilament $\mathrm{SiC}$ fibres from Textron are being produced with slightly carbon-rich rather than silicon-rich compositions (Morscher et al 1993; Schoenburg). The polymer-derived Hi-Nicalon SiC fibres are being processed to minimize the unstable and creep-prone oxygen-containing phases (Takeda et al 1992) and the sintered SiC fibres from Dow Corning and Carborundum and the chemically converted $\mathrm{SiC}$ fibres from MER Corporation are using processes which inherently eliminate second phases that enhance creep and creep related flaw growth. For short time exposures at high temperatures, these newer fibres are showing better strength retention and better fast fracture strength than the commercial SiC fibres. The improved strength retention follows from the fact that many of these fibres employ maximum processing temperatures well above $1200^{\circ} \mathrm{C}\left(2192^{\circ} \mathrm{F}\right)$, some to $1800^{\circ} \mathrm{C}\left(3272^{\circ} \mathrm{F}\right)$ and above. Thus fibre strength degradation under zero stress conditions should no longer be a significant issue in limiting CFCC fabrication temperatures. However, the issue remains whether these new fibres under structural loading can also improve CFCC long-time service temperatures.

In light of the above CFCC material needs, it follows that the ceramic fibres for high payoff, high temperature applications should qualitatively display all of the table 1 property needs. In terms of quantitative goals, the biggest challenge is, that the fibres should display sufficient high temperature strength and creep resistance to yield CFCC

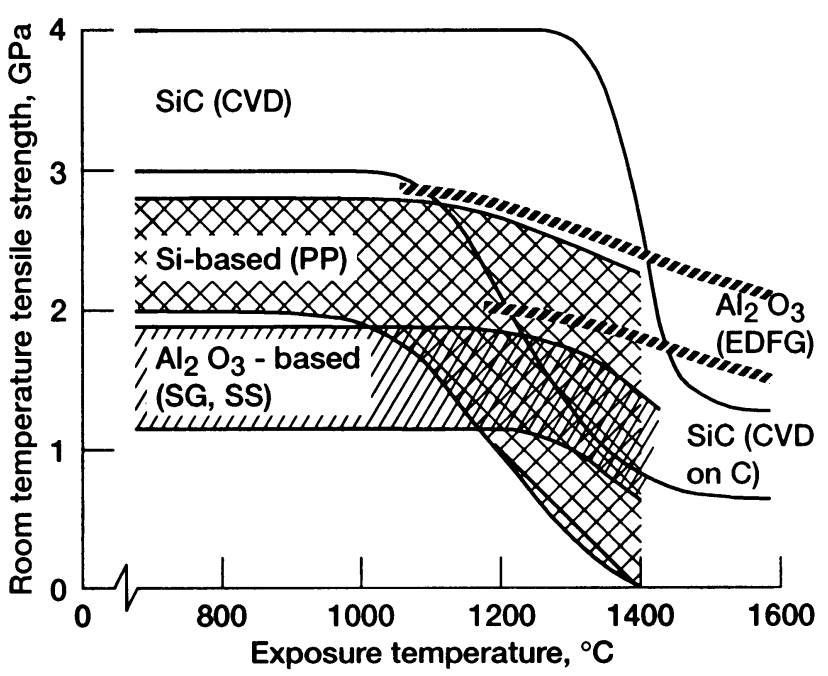

Figure 3. Room temperature strength retention after shorttime thermal exposure ( 1 to $10 \mathrm{~h}$ ) for commercial fibres based on silicon compounds and alumina.

Table 1. Key property needs for continuous fibres as reinforcement for high temperature CFCC.

\begin{tabular}{|c|c|}
\hline Fibre property need & CFCC benefit \\
\hline High modulus & Improves CFCC stiffness and reduces matrix stresses \\
\hline High as-produced strength & Improves CFCC toughness and ultimate strength \\
\hline High thermomechanical stability & $\begin{array}{l}\text { Improves CFCC as-fabricated strength and CFCC strength retention and creep resistance } \\
\text { during service }\end{array}$ \\
\hline High oxidative stability & Improves CFCC service life in oxidization environments \\
\hline Small diameter & Improves matrix strength and facilitates fabrication of thin and complex-shaped CFCC \\
\hline Low density & $\begin{array}{l}\text { Improves CFCC specific properties for weight-sensitive applications and reduces stresses } \\
\text { in CFCC rotating components }\end{array}$ \\
\hline Low cost & Reduces CFCC cost and improves CFCC commercial viability \\
\hline
\end{tabular}




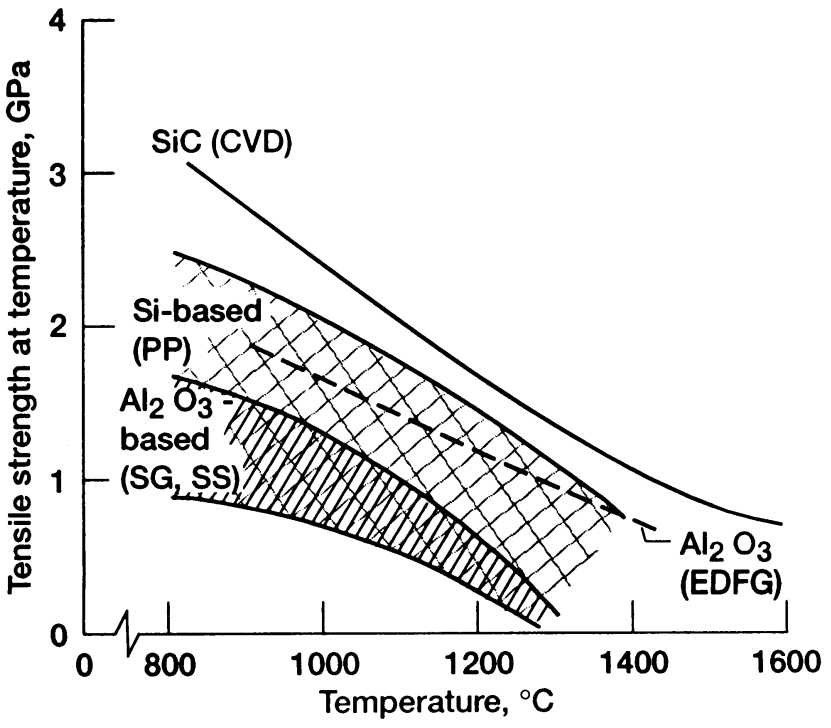

Figure 4. Fast-fracture strength at room temperature for commercial fibres based on silicon compounds and alumina.

with performance at least equivalent to the best superalloys, but at service temperatures above $1000^{\circ} \mathrm{C}$ $\left(1832^{\circ} \mathrm{F}\right)$. Since mechanical performance for many applications is evaluated on specific basis, the fibres should also have a sufficiently low density to provide the CFCC with high toughness and the capability to be fabricated into complex shapes and thin sections. Finally, the fibres should have sufficiently low cost so as not to adversely affect the overall CFCC fabrication cost.

\section{Composite processing}

In the area of composite processing, critical issues are, preparation of optimum matrix precursors, uniform precursor infiltration into fibre array, and matrix densification to high final density. Slurry infiltration technique was successfully used in fabricating SiC-glass matrix composites, which are typically hot-pressed at temperatures near or above the softening point of the glass, such that densification readily occurs with viscous flow of the matrix (Cornie et al 1996). On the other hand, the slurry infiltration and mixing technique has been less effective because of the need for higher processing temperatures necessary to densify $\mathrm{Si}_{3} \mathrm{~N}_{4} / \mathrm{SiC}$-based matrices. Also, fibre degradation and grain crystallization occur at higher processing temperatures including fibre-matrix chemical reactions. In addition, anisotropic behaviour resulting from preferred orientations induced by uniaxial hot pressing is a crucial factor which should be considered. Polymer pyrolysis technique offers lower processing temperatures around $1400^{\circ} \mathrm{C}\left(2552^{\circ} \mathrm{F}\right)$, compared to $1800-2000^{\circ} \mathrm{C}\left(3272-3632^{\circ} \mathrm{F}\right)$ required for hot pressing/sintering. However, the key issues in polymer pyrolysis process are the choice of proper precursors, high shrinkage, low yield and microcracking at the matrix. Further, development is necessary in order to improve the merits of the polymer pyrolysis technique to produce CFCC.

Chemical vapour deposition (CVD) and chemical vapour infiltration (CVI) techniques produce uniform coatings of tailored compositions, including multiple layers of different compositions. Currently CVI technique has demonstrated the greatest commercial success to form complex shaped CFCCs, including single continuous deposition step rather than multiple infiltration. However, a key issue is to achieve highly dense matrices. Surface reaction must remain rate controlling to progressively deposit a matrix to high density.

\section{Conclusions}

The present paper describes the importance of improved fracture toughness in producing high strength and reliable ceramics matrix composites for high-temperature structural applications in aerospace, military, and industrial applications. However, the greatest challenge to date is the development of high quality continuous ceramic fibres with associate coatings able to maintain their high strength in oxidizing environment at high temperature. Emphasis here has been placed on seven key properties (table 1), important for achieving structurally reliable CFCC at high temperatures. Application of CFCC is feasible and probably inevitable, although the exact time phasing is difficult to predict. However, the challenges to toughened-CFCCs will require broad scope of effort such as improved processing and properties composites, better understanding of all candidate composite systems, and further development of design/material interrelationship.

\section{References}

Cornie J A, Chiang Y-M, Uhlman D R, Mortensen A and Collins J M 1996 Am. Ceram. Soc. Bull. 65293

Campbell C X and Rahaiby E I (eds) 1995 Databook on mechanical and thermophysical properties of particulatereinforced ceramic matrix composites (West Lafayette, Indiana: Ceramics Information Analysis Centre, Purdue University) p. II-87

DiCarlo J A and Dutta S 1995 Handbook on continuous fibrereinforced ceramic matrix composites (eds) R Lehman, S K EIRahaiby and J B Wachtman Jr (West Lafayette, Indiana: Ceramics Information Analysis Centre, Purdue University) p. 137

Li C W and Yamanis J 1989 Ceram. Eng. Sci. Proc. 10632

Morscher G N, DiCarlo J A, Ning X J and Pirouz P 1993 Advances in ceramic-matrix composites ceramic transactions (Westerville, Ohio: Am. Ceram. Society) 38 p. 679

Sawaguchi A, Toda K and Niihara K 1991 J. Am. Ceram. Soc. 741142

Schoenburg T, Textron Speciality Materials (private communication)

Takeda M, Imai Y, Ichikawa H, Ishikawa T, Kasai N, Seguchi T and Okamura K 1992 Ceram. Eng. Sci. Proc. 13209 